Review Article

\title{
An Overview on Image Registration Techniques for Cardiac Diagnosis and Treatment
}

\author{
Azira Khalil $\mathbb{D}^{1,2}$ Siew-Cheok Ng, ${ }^{1}$ Yih Miin Liew $\mathbb{D}^{1},{ }^{1}$ and Khin Wee Lai ${ }^{1}$ \\ ${ }^{1}$ Department of Biomedical Engineering, Faculty of Engineering, University of Malaya, 50603 Kuala Lumpur, Malaysia \\ ${ }^{2}$ Faculty of Science and Technology, Islamic Science University of Malaysia, 71800 Nilai, Negeri Sembilan, Malaysia \\ Correspondence should be addressed to Khin Wee Lai; lai.khinwee@um.edu.my
}

Received 8 March 2018; Revised 5 July 2018; Accepted 17 July 2018; Published 8 August 2018

Academic Editor: Gani Bajraktari

Copyright (c) 2018 Azira Khalil et al. This is an open access article distributed under the Creative Commons Attribution License, which permits unrestricted use, distribution, and reproduction in any medium, provided the original work is properly cited.

Image registration has been used for a wide variety of tasks within cardiovascular imaging. This study aims to provide an overview of the existing image registration methods to assist researchers and impart valuable resource for studying the existing methods or developing new methods and evaluation strategies for cardiac image registration. For the cardiac diagnosis and treatment strategy, image registration and fusion can provide complementary information to the physician by using the integrated image from these two modalities. This review also contains a description of various imaging techniques to provide an appreciation of the problems associated with implementing image registration, particularly for cardiac pathology intervention and treatments.

\section{Introduction}

Cardiovascular disease $(\mathrm{CVD})$ remains the leading cause of death around the world. It accounts for an estimated 17.7 million deaths in 2015 , representing $31 \%$ of all global deaths [1]. Table 1 shows a percentage breakdown of the deaths due to CVDs around the globe. As shown in the table, 8.7 million were attributed to ischemic heart disease and 6.2 million to stroke. Rheumatic heart disease, such as heart valve disease, accounts for 0.3 million deaths. Hypertensive heart diseases, such as heart failure, thickening of the heart muscle, and coronary artery disease, account for 0.9 million deaths. Moreover, 0.4 million deaths were attributed to inflammatory heart diseases, such as cardiomyopathy, myocarditis, and endocarditis. Approximately 1.0 million deaths were due to other circulatory diseases. These epidemiologic data show that CVD is today the largest single contributor to global mortality, and the World Health Organization estimates that CVD will continue to dominate mortality trends in the future. Thus, additional efforts should be aimed at diagnosing and treating the CVD to improve patient's health and decrease this alarming mortality rate.

Medical imaging plays a vital role in the diagnosis of cardiac diseases. There are several imaging modalities that can diagnose cardiac diseases, for example, X-ray, echocardiography, single-photon emission computed tomography (SPECT), positron emission tomography (PET), CT, and magnetic resonance imaging (MRI). Imaging the heart with a single modality will provide the physician with insufficient information regarding the heart's condition. The heart is indeed a nonrigid but dynamic structure. Heart deformation inevitably occurs during the cardiac pumping cycle. As each imaging modality provides unique information and overcomes only certain challenges in cardiac imaging, the physician usually prescribes more than one imaging procedure to gather as much information of the heart's condition before making a treatment decision. Imaging modality also plays important roles during interventional cardiac treatment. Some imaging modalities, such as echocardiography and fluoroscopy/angiography, are often used during interventional procedures to provide visual aid to the physician. In certain clinical cases, multiple images are acquired at different time points or from different viewpoints. Images can also be taken with differing imaging modalities. Thus, image fusion is often useful for the integration of various sources of information. It involves a principal step of image registration. 
TABle 1: Percentage breakdown of deaths due to CVDs in 2015 [1].

\begin{tabular}{lc}
\hline Types of CVD & $\begin{array}{c}\text { Percentage of } \\
\text { death (\%) }\end{array}$ \\
\hline Rheumatic heart disease & 1.73 \\
Hypertensive heart disease & 5.33 \\
Ischemic heart disease & 49.50 \\
Stroke & 35.30 \\
Ischemic stroke & 16.46 \\
Hemorrhagic stroke & 18.82 \\
Cardiomyopathy, myocarditis, and endocarditis & 2.34 \\
Other circulatory diseases & 5.83 \\
\hline
\end{tabular}

In the biomedical research field, image registration is an ongoing research. In 1992, Brown [2] performed a comprehensive survey on different registration methods. This was followed by thorough reviews describing the state-ofthe-art registration algorithms and applications by Maintz and Viergever [3], Audette et al. [4], Hill et al. [5], and Zitová and Flusser [6]. Lester and Arridge [7] and Hill et al. [5] provided reviews focusing on image registration in the medical field, whereas Makela et al. [8] and Zitová and Flusser [6] provided reviews on cardiac image registration. Multimodality image registration of cardiac structures is a complicated process relative to the fusion of other body parts, such as the brain or kidney, due to the heart and thorax motions as well as the deformable nature of the heart. This study aims to provide an overview on image registration research performed using various imaging modalities, purpose of image registration in cardiovascular imaging, and implementation strategies of image registration.

\section{Medical Imaging Modalities for Cardiac Imaging}

2.1. Chest X-Ray. Chest X-ray (CXR) examination is almost often prescribed as the first imaging procedure for a patient with suspected cases of heart or lung disease. It is a noninvasive imaging procedure where a small amount of X-ray radiation is used to expose the chest in creating a static projection image on the detector [9]. CXR provides structural information, including the location, size, and shape of the heart as well as the lungs and bones of the chest. However, it cannot determine the internal heart structure due to the loss of depth information. Therefore, heart disease cannot be accurately diagnosed based on CXR alone. Current advances in dual-energy (DE) CXR have many advantages over conventional chest radiography, facilitating cardiac image interpretation. With additional techniques of image registration, coronary artery calcium can be identified using DE CXR $[10,11]$. However, the use of radiation in the imaging procedure also confounds the use of this modality for real-time imaging; therefore, no functional information of the heart can be obtained.

2.2. Angiography. Angiography is another imaging modality that also utilizes $\mathrm{X}$-ray radiation to image the heart. This procedure requires injection of a radiocontrast agent into the blood vessel, and a low-dose X-ray beam is used to create real-time images of the heart based on fluoroscopy [12]. In ischemic heart disease such as coronary artery disease, angiography can be used to identify the infarct region $[13,14]$. In addition, this imaging procedure is used for left ventricular (LV) [15] lead implantation during cardiac resynchronization therapy for patients suffering from heart failure [16-18]. Angiography is also useful for guiding the physician during cardiac electrophysiology procedures for patients with cardiac arrhythmias [19-21]. Furthermore, angiography can be applied to congenital heart disease patients during cardiac catheterization procedures [22, 23]. However, this procedure is contraindicated for patients who are allergic to contrast agents and is a high risk for hypertensive patients. Furthermore, due to the radiation exposure over an extended period of time during the procedure, it is also not recommended for pregnant women and children due to the risk of radiation.

2.3. Myocardial Perfusion Imaging (MPI). MPI is another noninvasive type of heart examination that uses nuclear medicine imaging techniques such as SPECT and PET [24]. This imaging procedure uses a small quantity of radioactive materials (radiotracer) that are typically injected into the blood vessel, inhaled, or swallowed. The radiotracer travels to the target area and gives off gamma rays, which are detected by a gamma camera and computer to process the images of the examined structure. MPI provides information on blood flow and heart function for the detection of coronary artery disease as well as the extent of coronary stenosis [25]. It also assesses the damage to the heart following a heart attack [25]. SPECT can also be used during LV tachycardia ablation procedures [26] for patients with cardiac arrhythmias. Other than detecting heart diseases, SPECT and PET are also used to improve attenuation correction [27-29] and respiratory motion during MPI [15, 25, 30-39]. However, MPI is limited by poor system resolution, and localization of the affected anatomical site has been reported to be difficult [40].

An important advance in the design of SPECT and PET scanner is the introduction of hybrid SPECT-CT/MR $[41,42]$ and PET-CT/MR machines [41, 43]. These hybrid machines allow examinations to be performed while the patient remains in the same examination table. Thus, this scanner reduces the imaging time, which interprets into increased patient comfort and cooperation. The hybrid scanner uses CT or MR images as transmission images for attenuation correction of the SPECT or PET imaging. The scanner then performs registration of the transmission images with the SPECT or PET images immediately after the CT or MRI. After image reconstruction, both imaging data are displayed either side by side or overlaid. The physician can gain both functional information by SPECT or PET imaging and accurate anatomical information of abnormal metabolic activity by CT or MR examination. Although these hybrid machines are designed to inherently solve the image fusion between imaging, additional image registration procedures are still implemented if severe movement of 
patients occurs between the SPECT or PET and CT or MR imaging [43].

2.4. CT. Cardiac CT produces cross-sectional images of the heart structure. It represents the X-ray attenuation properties of the tissue being imaged [44]. Thin X-ray radiations are used to scan the FOV and yield line attenuation measures at all possible angles of the body being imaged. The line attenuation measures are used to reconstruct the $3 \mathrm{D}$ attenuation map of the body with each point on the map carrying the value of X-ray attenuation coefficient. Spiral or sequential technique can be used to reconstruct the $3 \mathrm{D}$ image of the heart. Additionally, contrast agents can also be used to enhance the visualization of blood vessels and identify the presence of tumors because of the difference in contrast uptake between tumors and surrounding normal tissue.

Cardiac CT is commonly applied as a preoperative imaging tool, while multi-slice CT angiography (CTA) is a promising technology for imaging patients with suspected coronary artery disease [45]. In addition, CT and CTA are widely used for calcium scoring for patients with the risk of coronary heart disease [46]. Recent advances in deformable registration techniques have enabled CT scan to identify regional infarction in heart disease patients [47] and aneurysm morphodynamics [48]. Furthermore, volumetric CT scans also provide essential information critical in treatment planning, including the morphology of the valves and stenosis severity [49-51]. However, cardiac CT cannot be utilized as a real-time intraprocedural guidance due to the use of high-dose ionizing radiation. It also cannot provide information on hemodynamics such as transvalvular pressure gradients and cannot detect valve regurgitation [52].

2.5. MRI. Similar to cardiac CT, cardiac MRI can also provide 3D cross-sectional images of the heart. MRI examination utilizes strong magnetic field to produce maps of atomic nuclei (hydrogen atoms in water or fat molecules in the body) [53]. The spin of atomic nuclei can be considered as a magnetic vector, causing the proton to behave like a magnet. The image acquisition involves an initial sequence of exciting pulses and recording of the emitted signal. The amplitude of the signal is then used to generate maps showing the heart structures. MRI produces images with high resolution as well as high tissue contrast useful for the assessment of heart chambers [54-57], heart valves [58, 59], size and blood flow through the major vessels [60], and surrounding structures such as the pericardium [61]. MRI is also utilized in diagnosing a variety of cardiovascular disorders such as tumors $[62,63]$ and inflammatory conditions.

Research has also been performed to evaluate the effects of coronary artery diseases, such as limited blood flow to the heart muscle and scarring within the heart muscle followed by heart attack $[64,65]$, using MRI. In addition, MRI can be utilized for the preoperative treatment planning procedure [66] and monitoring the progression of certain disorders over time $[67,68]$. Furthermore, MRI can evaluate the anatomy of the heart and blood vessels $[69,70]$ as well as the effect of surgical changes $[71,72]$, especially in patients with congenital heart diseases [59, 61]. In addition, MRI provides information about cardiac necrosis and fibrosis through late gadolinium-enhanced imaging, iron overload measurement, and myocardial tissue characterization by relaxometry [73]. However, compared with cardiac CT, these examinations are much more expensive and contraindicated for patients with metallic implants such as graft stents, cardiac pacemaker devices, or hemodynamic support devices. Although MRI is the gold standard for cardiac assessment, its resolution is still insufficient to resolve valve leaflets. Therefore, MRI is not feasible for surgical planning of valvular diseases.

2.6. Echocardiography. Echocardiography is the ultrasound (US) imaging of the heart. It is a vital imaging examination for diagnosing heart disease. The basic working principle of echocardiography involves the generation of high-frequency sound waves by a US probe, which is directed toward the tissue. A portion of the sound waves that penetrates the tissue are reflected back toward the transducer when the waves encounter boundaries of tissues with different reflective indices. The reflected signals are detected and processed by the echocardiography system to reconstruct images of the heart structures. Currently, two-dimensional (2D) echocardiography is the main preoperative imaging modality for cardiac pathologies.

In valvular disease, this modality allows clinicians to estimate the degree of valve regurgitation or stenosis, valve annular size, involvement of the leaflets, chordal and papillary muscle structural integrity, and overall LV size and LV systolic function [74-77]. Echocardiography also plays a significant role in hypertensive patients as it provides information on LV mass [15], LV systolic function, impaired LV diastolic function, and left atrial (LA) size and function $[78,79]$. In addition, coronary artery disease can also be detected using this intravascular US (IVUS) technology [80, 81]. Echocardiography provides screening for early cardiac disease detection and intervention for rheumatic heart disease and ischemic heart disease [82-84]. It can also be used for intraoperative image guidance to facilitate physicians in surgery due to its real-time capability without the use of ionizing radiation [55, 85-95]. It is also a low-cost option relative to other imaging modalities [96]. However, the quality of echocardiography images is inferior compared with other imaging modalities such as cardiac CT and MRI due to the presence of speckle noise and limited field of view (FOV) [97].

Another type of echocardiography is transesophageal echocardiography (TEE). TEE provides detailed images of cardiac structures near the upper chambers, such as heart muscle and chambers, valves, pericardium, and blood vessels connected to the heart. It is also utilized during cardiac treatment procedures to assist device positioning and deployment. However, compared with 2D echocardiography, TEE is an invasive procedure because images are acquired by passing a thin tube attached with an echo probe through the patient's mouth, down the throat into the esophagus [98]. Furthermore, due to the long duration of cardiac treatment, 
continuous TEE monitoring usually requires general anesthesia with endotracheal intubation. By contrast, intracardiac echocardiography (ICE) can be prescribed to aid such procedures. Similar to the technique of IVUS, the ICE is a catheter-based imaging that provides images within the heart. Compared with the limited view provided by TEE, the echo probe attached to the catheter in ICE can be maneuvered within the heart, thus providing more detailed images within the heart as well as aortic root images. Unlike TEE, ICE requires only local anesthesia, which reduces the risk and discomfort of endotracheal intubation, esophageal intubation, and general anesthesia associated with TEE [99].

Three-dimensional (3D) echocardiography can provide real-time $3 \mathrm{D}$ visualizations of the heart structure and overcome some of the limitations of conventional 2D echocardiography $[74,79,94]$. Unfortunately, such technology is not widely available and expensive compared with 2D echocardiography.

\section{Purpose of Image Registration in Cardiac Imaging}

The purpose of image registration is to align images with respect to each other. The result of image processing can help in further medical image analysis for various purposes, including correlating clinical features from different cardiac images, respiratory motion correction, facilitating the cardiac segmentation procedure, complementary information for image fusion, and image guidance for therapeutic intervention.

\subsection{Facilitation of Image Segmentation. Cardiac analysis} includes the calculation of structural and functional cardiac indices. Such indices include chamber volumes, stroke volume, ejection fraction, cardiac output, myocardial mass, and myocardial wall thickness and thickening. These indices can be calculated by segmenting the heart chambers [100]. However, delineating the heart manually on multiple slices and frames requires a considerable amount of time. Furthermore, this is subject to well-established intra- and intersubject variability. Thus, current advances in image registration techniques have adopted automated cardiac segmentation techniques that can rapidly, objectively, and accurately extract the chamber boundaries from medical images in clinical practice. Among the four chambers, the $\mathrm{LV}$ has received the most attention in image registration for cardiac segmentation $[21,57,64,101-110]$. This is because it plays a key role on the process of blood circulation, and thus, its function/dysfunction is associated with most cardiac diseases. Furthermore, the LV has a relatively simple geometry with thick myocardial walls, making its automated segmentation more feasible. Compared with LV, studies on image registration for the segmentation of the right ventricle (RV) $[107,111]$ and LA $[65,112,113]$ are few due to the more complex geometry of these chambers and their much thinner walls. However, these chambers are associated with many critical diseases, such as modeling in patients with pulmonary hypertension $[111,114]$ or LA enlargement
$[65,112,113,115,116]$. Further research is thus required to develop techniques capable of coping with the difficulties of segmenting complex RV and right atrial walls and to segment the whole heart to enable an assessment that takes into account the combined motion of all chambers.

3.2. Respiratory Motion Correction. Dynamic motion of the heart, spatial errors due to systole and diastole, and phasic changes during respiration can cause changes in size and position of the heart during cardiac imaging, thus significantly impairing the image quality and diagnostic accuracy of cardiac image analysis. Gating to both the cardiac cycle and respiration can potentially help to reduce these errors. However, another source of error due to varying patient positions between imaging modalities can still produce motion artifacts during the cardiac imaging and interventional procedure. Cardiac motion can be estimated using the deformable registration scheme performed on initial images of different cardiac phases. This motion information can be used for a motion-compensated reconstruction, allowing the use of all acquired data for image reconstruction [117]. The image registration plays an important role in motion correction during coronary angiography [117-120], SPECT [15, 27, 35-38, 121], PET [28, 122-125], CT [31, 126-129], MRI [56, 130-135], and echocardiography [136, 137]. The respiratory motion also allows the use of predictive models that compute information about the respiratory cycle and use them for image registration techniques [138].

3.3. Direct Surgical Guidance. Minimally invasive transcatheter cardiac interventions are being adopted rapidly to treat a range of CVDs such as valve repairs and implantation [76, 87, 88, 90, 91, 93, 139, 140], atrial fibrillation therapy, and bypass surgery [141]. 2D echocardiography and fluoroscopy/angiography have been used as intraoperative imaging modalities to provide surgical guidance to clinicians owing to their real-time in vivo functionality. Despite the aforementioned advantage, the image quality of echocardiography is confounded by speckle noise and limited FOV, therefore appearing inferior compared with other preoperative modalities such as CT or MRI [97]. Moreover, 2D echocardiography and fluoroscopy/angiography provide only planar images. Issues associated with maintaining both the surgical tool and the anatomical targets in the same view during surgery have also been reported [142]. By contrast, the preoperative imaging modalities such as CT and MRI play an important role in surgical planning and simulation of cardiac interventions. Overlaying a 3D cardiac model extracted from preoperative images onto real-time echocardiography or fluoroscopic images provides valuable visual guidance during the intervention. The principal step in this integration involves image registration techniques. As both images were acquired at different times and have distinct image properties, image registration can be applied to temporally and spatially align both images, thus providing better information during surgical guidance. Such integration has been applied using 2D echocardiography-CT 
$[87,90,91,93,143,144], 3 \mathrm{D}$ echocardiography-CT [91], and 2D echocardiography-MRI [145].

3.4. Image Fusion. Image registration is a principal step in image fusion. Image fusion can provide clinicians with complementary information from the integrated information from each modality. For example, echocardiography can provide functional information such as functional information of cardiac valves, valve regurgitation, stenosis, and systolic function and measure systolic ejection performance and the extent of wall hypertrophy. However, the image quality of echocardiography is inferior to other $3 \mathrm{D}$ imaging modalities due to the presence of speckle noise and limited FOV. The 3D imaging modalities such as CT and MRI can provide quantitative assessments on valve morphology, valvular dysfunction severity, and structural information of chambers and vessels. Thus, establishing direct spatial registration between these modalities can provide physicians with functional and structural information crucial to diagnosing and treatment planning of cardiac diseases $[55,88-95,146,147]$. The registration of SPECT-CT [148] and PET-CT [149-151] also facilitates information fusion of both modalities. Molecular and functional PET and SPECT imaging are used to assess myocardial perfusion, perfusion reserve, metabolism, and innervation. With registration to $\mathrm{CT}$, the calcification of coronary arteries can be detected and quantified.

\section{Implementation Strategy}

Image registration is a process that finds a transformation that maps features in one coordinate space to their location in another coordinate space [152]. It allows one to transfer information between both coordinate spaces. The basic steps in the image registration algorithm often involve feature extraction, geometrical transformation definition, similarity measure, and optimization. First, the feature space extracts the selected feature to be used for mapping. Second, the search space determines the degree of transformation that brings alignment between the fixed and moving images. Let us assume that there are two images to be spatially registered: the moving image, $R(x)$, which is defined over a domain $x \in V_{\mathrm{R}}$, and the fixed image, $S(x)$, which is defined over a domain $x \in V_{\mathrm{S}}$. Transformation, $T(x)$, is used to transform points in $R(x)$ to their corresponding positions in $S(x)$. The commonly used transformations include rigid, affine, projective, and curved transformations. A similarity measure is used to estimate the similarity merit of the fixed image and transform the moving image. The search for optimal transformation parameters to register the images spatially can be accomplished by optimizing (maximizing or minimizing) a similarity measure derived from features in the image, for example, the intensities of voxels in the images. The search process continues according to the optimization strategy until convergence, that is, transformation parameters that minimize or maximize the similarity measure are found $[152,153]$. Figure 1 shows an overview of implementation strategy approaches.

\subsection{Spatial Transformation}

4.1.1. Rigid and Nonrigid Transformation. In choosing the types of spatial transformation algorithms, assumptions on heart rigidity are generally made. In most cases, the heart is assumed to be a rigid body structure, where no changes or deformations occur from the time of imaging to the time of registration [79, 104, 154-164]. Rigid spatial transformation usually assumes the heart to be rigid with periodic heart motion throughout the imaging process. In rigid transformation methods, the entire $2 \mathrm{D}$ or $3 \mathrm{D}$ images are transformed. The basic rigid transformation methods include six degrees of freedom (or unknowns) in the transformation: three translations and three rotations. Another rigid transformation method that includes scaling and skew parameters is the affine transformation method. The affine rigid transformation can include up to nine degrees of freedom (three translations, three rotations, and three scaling parameters) or 12 degrees of freedom (three translations, three rotations, three scaling parameters, and three skews).

The rigid spatial transformation $[79,104,154-164]$ in the registration framework is commonly used in clinical practice and is considered to be acceptable for reaching the correct diagnosis [151]. Although this hypothesis is valid in some surgical scenarios, the heart is indeed a nonrigid but dynamic structure. Deformation of the heart inevitably occurs during the pumping cycle. Other factors such as respiration and probe and surgical instrument pressure on the skin can also contribute to the deformation of the heart. These factors can jeopardize the accuracy of image registration during real-time imaging.

Meanwhile, nonrigid spatial transformation utilizes nonaffine registration algorithms [79, 104, 154-164]. In some cases, the nonaffine transformation is applied after initial estimation given by rigid body or affine transformation [27, 123, 165-169]. Thin-plate splines are often used to determine the transformation [170-179]. Using intensity-based algorithms, the nonrigid component of the transformation can be determined using a linear combination of polynomial terms $[120,180]$, basis functions, or B-spline $[27,49,80,181-184]$ surfaces defined by a regular grid of control points. As an alternative, pseudophysical models, such as elastic deformation or fluid flow $[78,169,185-187]$, can be used, wherein the deformation between the images is modeled as a physical process. Some registration techniques also include a mixture of rigid and nonrigid transformations in the same algorithm such as nonaffine registration [156].

4.1.2. Dimensionality. Selection of spatial transformation algorithms also depends on the image dimensionality, whether involving the registration from $2 \mathrm{D}$ to $2 \mathrm{D}[10,11,136,171,183]$, $3 \mathrm{D}$ to $3 \mathrm{D}$ [22, 49, 74, 78, 139, 162, 179, 188, 189], or 2D to 3D $[79,92,93,143,190,191]$. For $2 \mathrm{D}$ to $2 \mathrm{D}$ registration, where the acquisition tightly controls the geometry of the images, the images can simply be registered via a rotation and two orthogonal translations. In addition, the scaling factor may also 

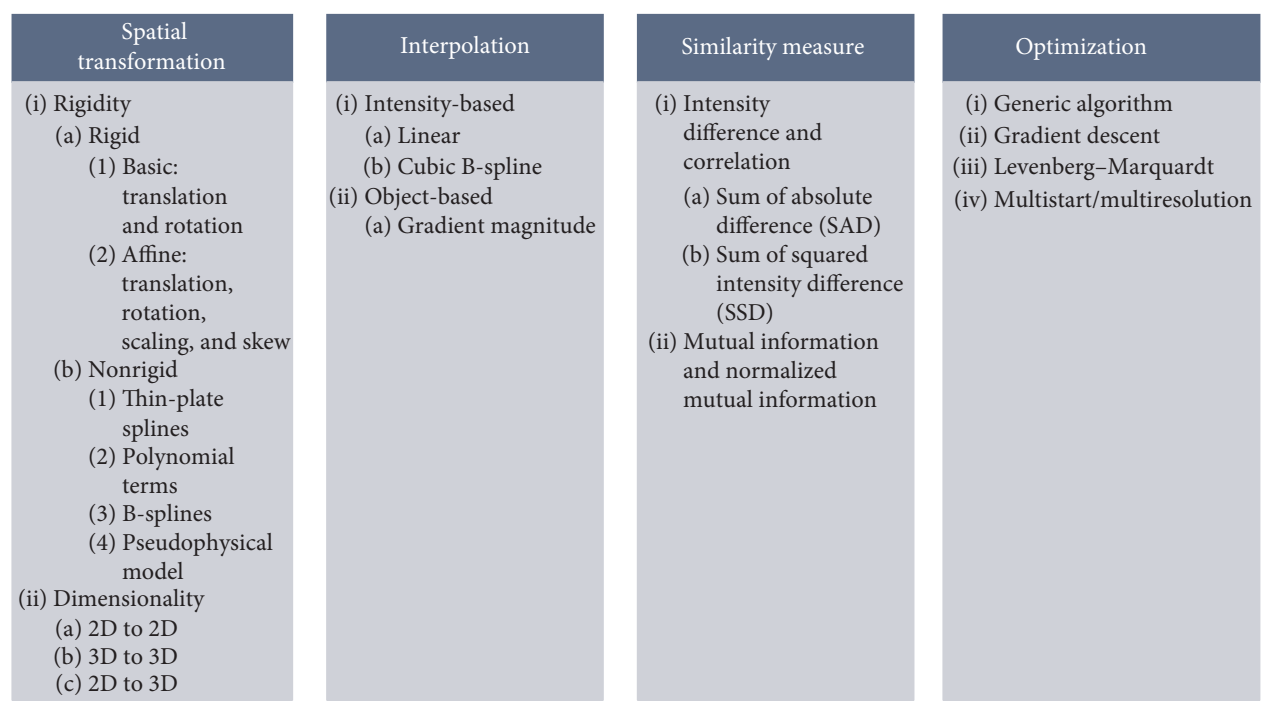

FIGURE 1: Different methods in the implementation strategy for cardiac image registration.

be considered from the real object to each of the images. Meanwhile, 3D to 3D registration is used to align tomography datasets or a single tomography image to any spatially defined information. This registration is based on the assumption that the internal anatomy of the patient is not distorted or changed in spatial relationships between organs. The $3 \mathrm{D}$ to $3 \mathrm{D}$ registration requires calibration on each scanning device to determine the scale of the scanned images. However, the registration of $2 \mathrm{D}$ to $3 \mathrm{D}$ images is more complex than that of $2 \mathrm{D}$ to $2 \mathrm{D}$ or $3 \mathrm{D}$ to $3 \mathrm{D}$ images. It involves establishing the concurrence between 3D volumes such as CT or MRI and planar images such as X-ray or optical images. Furthermore, they are needed when the position of one or more slices from tracked B-mode US, interventional CT, or interventional MR images is to be constructed regarding $3 \mathrm{D}$ volume. The $2 \mathrm{D}$ to $3 \mathrm{D}$ registration often has computational complexity, and the speed of registration is considered a problem.

4.2. Interpolation. The choice of interpolation method also plays a significant role during the image registration process. The interpolation method will sample input image in the same size, spatial location, and orientation as the image to be registered. Two types of interpolation methods exist: intensity-based interpolation and object-based interpolation. In intensity-based interpolation, the final result from the interpolation is directly computed from the intensity values of input images. Examples of intensitybased interpolation include linear $[92,93,162,192]$ and cubic B-spline [27, 49, 80, 181-184] interpolation methods. Given its computational simplicity, intensity-based interpolation has been widely used in cardiac image registration research. The resultant image is basically a weighted average of input image. However, the main limitation of these methods is the blurring effects on cardiac structure boundaries.

Meanwhile, in object-based interpolation, the extracted information from objects contained in input images is used to guide the interpolation into more accurate results. One of the object-based interpolation techniques is the gradient magnitude-based approach, which involves finding corresponding points between consecutive slices and then applying the linear interpolation to find in-between slices. In this technique, a small difference between consecutive slices is assumed; thus, the search for correspondence points to small neighborhoods is restricted. However, the limitation is that this assumption is not applicable in many cases. To reduce the blurriness of edges, more recent approaches have been studied, including the polynomial curve fitting $[120,180]$ method.

4.3. Similarity Measure. Similarity measures can be based on intensity difference and correlation methods or based on the mutual information method. Registration based on image intensity difference and correlation methods [129, 190, 193-197] is best for intramodality image registration because the method measures the similarity between images that differ primarily because of different image acquisition conditions (such as noise). For example, a study used the sum of absolute difference (SAD) and sum of squared intensity difference (SSD) similarity measures [79]. In the SAD method, registered images are subtracted pixel by pixel, and the mean value of the sum of the absolute intensity difference of all pixels in the subtracted image is computed. The SSD is similar to the SAD measure, but it is calculated instead of the absolute difference.

Registration based on mutual information or normalized mutual information [92, 93, 109, 131, 136, 139, 189, 198-204] uses a similarity metric in the registration process. This similarity measure is arguably an excellent similarity metric and has been shown to be robust and well suited for multimodal image registration. The method compares the information or entropy between images to arrive at its measure. The mutual information assumes that when images are perfectly registered, their shared entropy is minimized. 
4.4. Optimization. To register the images, an optimal value of the similarity measure over a parameter space with dimensionality defined by the number of degrees of freedom of the transformation is calculated. The optimization algorithm then makes another estimate of the transformation, evaluates the similarity measure again, and continues until the algorithm converges, at which point no transformation can be found that results in a better value of the similarity measure within a preset tolerance. Each registration algorithm that makes use of a voxel similarity measure tends to use a different optimization algorithm.

One of the optimization techniques used in cardiac image registration is genetic algorithms, which are known to be very robust for searching and optimization. It is based on the principles of natural biological evolution, which operates on a population of potential solutions applying the principle of survival of the fittest to produce better approximations to a solution. One of the examples of genetic optimization algorithms is the generalized pattern search (GPS) [92, 93]. The GPS algorithm does not involve the gradient of the objective function to be optimized; thus, it is specifically suited for function that is not differentiable, such as mutual information in its usual form. Other optimization methods include the gradient descent optimization method [80, 197] and Levenberg-Marquardt optimization method [160, 205] in minimizing the variance in intensities of corresponding pixels.

In addition, a multistart or multiresolution optimization method [80, 206-208] can be utilized to the registration workflow. These methods are one way to explore the transformation parameter space. Combined with other local optimization methods, they restart the search for the global optimum from a new solution once a region (or a path) has been explored by local optimization. The new start position is uniformly sampled from the transformation parameter space.

\section{Conclusion}

In this study, various imaging modalities and their purposes and implementation strategies in image registration for cardiac diagnosis and treatment are presented. Many imaging modalities are used for diagnosing cardiac diseases. Each imaging modality provides unique information and overcomes certain challenges in cardiac imaging. Multimodality imaging can provide physicians with more information of the heart's condition before making a treatment decision. The integration of image fusion from various types of imaging modalities involves a principal step of image registration. As the intent of image registration is to align images with respect to each other, image registration can assist physicians for further medical image analysis for various purposes, including correlating clinical features from different cardiac images, respiratory motion correction, facilitating the cardiac segmentation procedure, complementary information for image fusion, and image guidance for therapeutic intervention.

In the implementation strategy of cardiac image registration, the basic steps include feature extraction, geometrical transformation definition, and similarity measure and optimization. Although previous studies have achieved image registration goals, no single standard algorithm can be applied in aligning two modalities. The multimodality registration algorithms need to take into account factors such as heart rigidity, dimensionality of the image dataset, interpolation methods, types of similarity measures, and choices of optimization approaches. However, challenges remain in overcoming the deformation of the heart and the respiratory motion, which can affect the accuracy of image registration, especially during real-time imaging for guiding the treatment procedure. Although significant work has been made in addressing such an issue, there is much more room for the development of fully automatic cardiac image registration by taking into account heart deformation and respiratory motion in the future.

\section{Data Availability}

The data supporting this review are obtained from previously reported studies and datasets, which have been cited within the manuscript as references.

\section{Conflicts of Interest}

The authors have no conflicts of interest.

\section{Acknowledgments}

This work was supported in part by the Postgraduate Research Grant (PG027-2014B), the Ministry of Higher Education (FRGS-FP047-2014B), and the Islamic Science University of Malaysia (USIM/SLAB). The authors would like to thank Dr. Ahmad Khairuddin from the National Heart Institute, Kuala Lumpur, Malaysia, for the various discussions on cardiac diseases.

\section{References}

[1] World Health Organization, World Health Statistics 2016: Monitoring Health for the SDGs, Sustainable Development Goals, 2016, WHO Library Cataloguing-in-Publication Data, Geneva, Switzerland, 2017.

[2] L. G. Brown, "A survey of image registration techniques," ACM Computing Surveys, vol. 24, no. 4, pp. 325-376, 1992.

[3] J. B. A. Maintz and M. A. Viergever, "A survey of medical image registration,” Medical Image Analysis, vol. 2, no. 1, pp. 1-36, 1998.

[4] M. A. Audette, F. P. Ferrie, and T. M. Peters, "An algorithmic overview of surface registration techniques for medical imaging," Medical Image Analysis, vol. 4, no. 3, pp. 201-217, 2000.

[5] D. L. Hill, P. G. Batchelor, M. Holden, and D. J. Hawkes, "Medical image registration," Physics in Medicine and Biology, vol. 46, no. 3, pp. R1-R45, 2001.

[6] B. Zitová and J. Flusser, "Image registration methods: a survey," Image and Vision Computing, vol. 21, no. 11, pp. 977-1000, 2003.

[7] H. Lester and S. R. Arridge, "A survey of hierarchical nonlinear medical image registration," Pattern Recognition, vol. 32, no. 1, pp. 129-149, 1999. 
[8] T. Makela, P. Clarysse, O. Sipila et al., "A review of cardiac image registration methods," IEEE Transactions on Medical Imaging, vol. 21, no. 9, pp. 1011-1021, 2002.

[9] J. T. Bushberg, The Essential Physics of Medical Imaging, Lippincott Williams \& Wilkins, Philadelphia, PA, USA, 2002.

[10] D. Wen, K. Nye, B. Zhou, R. C. Gilkeson, and D. L. Wilson, "Coronary calcium visualization using dual energy chest radiography with sliding organ registration," in Proceedings of Medical Imaging 2016: Image Processing, vol. 9784, , March 2016.

[11] B. Zhou, D. Wen, K. Nye et al., "Detection and quantification of coronary calcium from dual energy chest $\mathrm{x}$-rays: phantom feasibility study," Medical Physics, vol. 44, no. 10, pp. 5106-5119, 2017.

[12] M. Moscucci, Grossman \& Baim's Cardiac Catheterization, Angiography, and Intervention, Lippincott Williams \& Wilkins, Philadelphia, PA, USA, 2013.

[13] H. Timinger, S. Kruger, K. Dietmayer, and J. Borgert, "Ultrasonicdiaphragm tracking for cardiac interventionalnavigation on 3D motion compensated static roadmaps," inMedical Imaging 2005: Visualization, Image-uide Procedures, and Display, Pts 1 and 2, vol. 5744, R. L. Galloway and K. R. Cleary, Eds., pp. 290-298, Proceedings of the Society of Photo-Optical Instrumentation Engineers, International Society for Optical Engineering (SPIE), Bellingham, WA, USA, 2005.

[14] D. F. Dauwe, D. Nuyens, S. De Buck et al., "Three-dimensional rotational angiography fused with multimodal imaging modalities for targeted endomyocardial injections in the ischaemic heart," European Heart Journal-Cardiovascular Imaging, vol. 15, no. 8, pp. 900-907, 2014, in English.

[15] J. Dey, W. P. Segars, P. H. Pretorius et al., "Estimation and correction of cardiac respiratory motion in SPECT in the presence of limited-angle effects due to irregular respiration," Medical Physics, vol. 37, no. 12, pp. 6453-6465, 2010, in English.

[16] A. Auricchio, A. Sorgente, E. Soubelet et al., "Accuracy and usefulness of fusion imaging between three-dimensional coronary sinus and coronary veins computed tomographic images with projection images obtained using fluoroscopy," Europace, vol. 11, no. 11, pp. 1483-1490, 2009, in English.

[17] R. Manzke, A. Bornstedt, A. Lutz et al., "Respiratory motioncompensated overlay of surface models from cardiac MR oninterventional X-ray fluoroscopy for guidance of cardiacresynchronization therapy procedures," in Medical Imaging 2010: Visualization, Image-Guided Procedures, and Modeling, K. H. Wong and M. I. Miga, Eds., vol. 7625, International Society for Optical Engineering (SPIE), San Diego, CA, USA, March 2010.

[18] S. G. Duckett, M. R. Ginks, B. R. Knowles et al., "Advanced image fusion to overlay coronary sinus anatomy with realtime fluoroscopy to facilitate left ventricular lead implantation in CRT," Pacing and Clinical Electrophysiology, vol. 34, no. 2, pp. 226-234, 2011.

[19] Y. L. Ma, A. P. King, N. Gogin et al., "Clinical evaluation of respiratory motion compensation for anatomical roadmap guided cardiac electrophysiology procedures," IEEE Transactions on Biomedical Engineering, vol. 59, no. 1, pp. 122-131, 2012.

[20] M. Panayiotou, K. S. Rhode, A. P. King et al., "Image-based view-angle independent cardiorespiratory motion gating and coronary sinus catheter tracking for $\mathrm{x}$-ray-guided cardiac electrophysiology procedures," Physics in Medicine and Biology, vol. 60, no. 20, pp. 8087-8108, 2015, in English.
[21] J. Y. Wielandts, S. D. Buck, K. Michielsen et al., "Multi-phase rotational angiography of the left ventricle to assist ablations: feasibility and accuracy of novel imaging," European Heart Journal-Cardiovascular Imaging, vol. 17, no. 2, pp. 162-168, 2016, in English.

[22] M. Glockler, J. Halbfass, A. Koch, S. Achenbach, and S. Dittrich, "Multimodality 3D-roadmap for cardiovascular interventions in congenital heart disease-a single-center, retrospective analysis of 78 cases," Catheterization and Cardiovascular Interventions, vol. 82, no. 3, pp. 436-442, 2013, in English.

[23] S. Goreczny, P. Dryzek, G. J. Morgan, M. Lukaszewski, J. A. Moll, and T. Moszura, "Novel three-dimensional image fusion software to facilitate guidance of complex cardiac catheterization," Pediatric Cardiology, vol. 38, no. 6, pp. 1133-1142, 2017, in English.

[24] P. Cremer, R. Hachamovitch, and B. Tamarappoo, "Clinical decision making with myocardial perfusion imaging in patients with known or suspected coronary artery disease," Seminars in Nuclear Medicine, vol. 44, no. 4, pp. 320-329, 2014.

[25] M. Marinelli, A. Martinez-Möller, B. Jensen et al., "Registration of myocardial PET and SPECT for viability assessment using mutual information," Medical Physics, vol. 37, no. 6, pp. 2414-2424, 2010, in English.

[26] M. F. Smith, X. Gibert-Serra, F. Arrate et al., "CardioViewer: a novel modular software tool for integrating cardiac electrophysiology voltage measurements and PET/SPECT data," in Proceedings of 2014 IEEE Nuclear Science Symposium and Medical Imaging Conference (NSS/MIC), p. 3, Seattle, WA, USA, November 2014 in English.

[27] D. Zhang, B. H. Yang, N. Y. Wu, and G. S. P. Mok, "Respiratory average CT for attenuation correction in myocardial perfusion SPECT/CT," Annals of Nuclear Medicine, vol. 31, no. 2, pp. 172-180, 2017, in English.

[28] P. J. Slomka, M. Rubeaux, L. Le Meunier et al., "Dual-gated motion-frozen cardiac PET with flurpiridaz F 18," Journal of Nuclear Medicine, vol. 56, no. 12, pp. 1876-1881, San Diego, CA, USA, 2015, in English.

[29] C. Y. Bai and R. Conwell, "A new technique to systematicallyminimize misregistration introduced errors in cardiac perfusionstudies with attenuation correction," in Proceedings of 2012 IEEE Nuclear Science Symposium and Medical Imaging Conference Record (IEEE Nuclear Science Symposium Conference Record), B. Yu, Ed., pp. 3157-3160, IEEE, Anaheim, CA, USA, October 2012.

[30] S. Redgate, D. C. Barber, A. Abdallah, and T. B. Wendy, "Using a registration-based motion correction algorithm to correct for respiratory motion during myocardial perfusion imaging," Nuclear Medicine Communications, vol. 34, no. 8, pp. 787-795, 2013, in English.

[31] A. Martinez-Moller, M. Souvatzoglou, N. Navab, M. Schwaiger, and S. G. Nekolla, "Artifacts from misaligned CT in cardiac perfusion PET/CT studies: frequency, effects, and potential solutions," Journal of Nuclear Medicine, vol. 48, no. 2, pp. 188-193, 2007, in English.

[32] A. Juslin, J. Lotjonen, S. V. Nesterov, K. Kalliokoski, J. Knuuti, and U. Ruotsalainen, "Alignment of 3-dimensional cardiac structures in O-15-labeled water PET emission images with mutual information," Journal of $\mathrm{Nu}$ clear Cardiology, vol. 14, no. 1, pp. 82-91, 2007, in English.

[33] F. Gigengack, L. Ruthotto, M. Burger, C. H. Wolters, X. Y. Jiang, and K. P. Schafers, "Motion correction in dual gated cardiac PET using mass-preserving image 
registration," IEEE Transactions on Medical Imaging, vol. 31, no. 3, pp. 698-712, 2012, in English.

[34] J. Dey, T. Pan, D. J. Choi et al., "Estimation of cardiac respiratory-motion by semi-automatic segmentation and registration of non-contrast-enhanced 4D-CT cardiac datasets," IEEE Transactions on Nuclear Science, vol. 56, no. 6, pp. 3662-3671, 2009, in English.

[35] J. G. Parker, B. A. Mair, and D. R. Gilland, "Respiratory motion correction in gated cardiac SPECT using quaternionbased, rigid-body registration," Medical Physics, vol. 36, no. 10, pp. 4742-4754, 2009, in English.

[36] J. Dey, W. P. Segars, P. H. Pretorius, and M. A. King, "Estimation and correction of irregular respiratory motion of the heart in presence of partial angle effects due to amplitude binning in SPECT," in Proceedings of 2008 IEEE Nuclear Science Symposium and Medical Imaging Conference (IEEE Nuclear Science Symposium Conference Record, p. 2931, IEEE, Orlando, FL, USA, October 2008.

[37] J. Dey and M. A. King, "Non-rigid full torso respiratory motion correction of SPECT studies," in Proceedings of 2010 IEEE Nuclear Science Symposium Conference Record (IEEE Nuclear Science Symposium Conference Record, pp. 23562358, IEEE, Knoxville, TN, USA, October 2010.

[38] J. Dey, K. J. Johnson, P. H. Pretorius, J. Mitra, and M. A. King, "Impact of variability in respiration on estimation and correction of respiratory motion of the heart in SPECT," in Proceedings of 2007 IEEE Nuclear Science Symposium Conference Record (IEEE Nuclear Science Symposium-Conference Record), vol. 1-11, pp. 4503-4509, IEEE, Honolulu, HI, USA, October 2007.

[39] U. E. Aladl, G. A. Hurwitz, D. Dey, D. Levin, M. Drangova, and P. J. Slomka, "Automated image registration of gated cardiac single-photon emission computed tomography and magnetic resonance imaging," Journal of Magnetic Resonance Imaging, vol. 19, no. 3, pp. 283-290, 2004, in English.

[40] J. R. Ballinger, "Pitfalls and limitations of SPECT, PET, and therapeutic radiopharmaceuticals," Seminars in Nuclear Medicine, vol. 45, no. 5, pp. 470-478, 2015.

[41] A. Flotats, J. Knuuti, M. Gutberlet et al., "Hybrid cardiac imaging: SPECT/CT and PET/CT. A joint position statement by the European Association of Nuclear Medicine (EANM), the European Society of Cardiac Radiology (ESCR) and the European Council of Nuclear Cardiology (ECNC)," European Journal of Nuclear Medicine and Molecular Imaging, vol. 38, no. 1, pp. 201-212, 2011.

[42] J. Lamb and J. P. Holland, "Advanced methods for radiolabeling multimodality nanomedicines for SPECT/MRI and PET/MRI," Journal of Nuclear Medicine, vol. 59, no. 3, pp. 382-389, 2017.

[43] C. Munoz, K. P. Kunze, R. Nej et al., "Motion-corrected whole-heart PET-MR for the simultaneous visualisation of coronary artery integrity and myocardial viability: an initial clinical validation," European Journal of Nuclear Medicine and Molecular Imaging, pp. 1-12, 2018.

[44] M. Mahesh and D. D. Cody, "Physics of cardiac imaging with multiple-row detector CT," Radiographics, vol. 27, no. 5, pp. 1495-1509, 2007.

[45] D. Ropers, "Detection of coronary artery stenoses with thinslice multi-detector row spiral computed tomography and multiplanar reconstruction," Circulation, vol. 107, no. 5, pp. 664-666, 2003.

[46] G. Y. Yang, Y. Chen, X. F. Ning, Q. Y. Sun, H. Z. Shu, and J. L. Coatrieux, "Automatic coronary calcium scoring using noncontrast and contrast CT images," Medical Physics, vol. 43, no. 5, pp. 2361-2373, 2016, in English.

[47] K. C. L. Wong, M. Tee, M. Chen, D. A. Bluemke, R. M. Summers, and J. H. Yao, "Regional infarction identification from cardiac CT images: a computer-aided biomechanical approach," International Journal of Computer Assisted Radiology and Surgery, vol. 11, no. 9, pp. 1573-1583, 2016, in English.

[48] A. Firouzian, R. Manniesing, C. T. Metz et al., "Quantification of intracranial aneurysm morphodynamics from ECG-gated CT angiography,” Academic Radiology, vol. 20, no. 1, pp. 52-58, 2013, in English.

[49] X. Zhenzhen, B. Tao, Y. Li et al., "3D fusion framework for infarction and angiogenesis analysis in a myocardial infarct minipig model," Molecular Imaging, vol. 16, p. 10, 2017, in English.

[50] B. M. White, S. Vennarini, L. Lin et al., "Accuracy of routine treatment planning 4-dimensional and deep-inspiration breath-hold computed tomography delineation of the left anterior descending artery in radiation therapy," International Journal of Radiation Oncology Biology Physics, vol. 91, no. 4, pp. 825-831, 2015, in English.

[51] D. Messika-Zeitoun, J.-M. Serfaty, J.-P. Laissy et al., "Assessment of the mitral valve area in patients with mitral stenosis by multislice computed tomography," Journal of the American College of Cardiology, vol. 48, no. 2, pp. 411-413, 2006.

[52] E. J. Chun, S. I. Choi, C. Lim et al., "Aortic stenosis: evaluation with multidetector CT angiography and MR imaging," Korean Journal of Radiology, vol. 9, no. 5, pp. 439-448, 2008.

[53] C. Constantinides, Protocols and Methodologies in Basic Science and Clinical Cardiac MRI, Springer, Berlin, Germany, 2017.

[54] C. Mekkaoui, T. G. Reese, M. P. Jackowski et al., "Diffusion tractography of the entire left ventricle by using freebreathing accelerated simultaneous multisection imaging," Radiology, vol. 282, no. 3, pp. 850-856, 2017, in English.

[55] V. Tavakoli, M. Kendrick, M. Shakeri, M. Alshaher, M. F. Stoddard, and A. Amini, "A multimodal (MRI/ultrasound) cardiac phantom for imaging experiments," in Proceedings of Medical Imaging 2013: Biomedical Applications in Molecular, Structural, and Functional Imaging, J. B. Weaver and R. C. Molthen, Eds., vol. 8672, International Society for Optical Engineering (SPIE), San Diego, CA, USA, March 2013.

[56] S. Weingartner, M. Akçakaya, S. Roujol et al., "Freebreathing combined three-dimensional phase sensitive late gadolinium enhancement and T-1 mapping for myocardial tissue characterization," Magnetic Resonance in Medicine, vol. 74, no. 4, pp. 1032-1041, 2015, in English.

[57] D. Wei, Y. Sun, S. H. Ong, P. Chai, L. L. Teo, and A. F. Low, "Three-dimensional segmentation of the left ventricle in late gadolinium enhanced MR images of chronic infarction combining long- and short-axis information," Medical Image Analysis, vol. 17, no. 6, pp. 685-697, 2013, in English.

[58] A. W. Dowsey, J. Keegan, M. Lerotic, S. Thom, D. Firmin, and G. Z. Yang, "Motion-compensated MR valve imaging with $\mathrm{COMB}$ tag tracking and super-resolution enhancement," Medical Image Analysis, vol. 11, no. 5, pp. 478-491, 2007, in English.

[59] M. Hamon, F. Burzotta, C. Oppenheim et al., "Silent cerebral infarct after cardiac catheterization as detected by diffusion weighted magnetic resonance imaging: a randomized 
comparison of radial and femoral arterial approaches," Trials, vol. 8, no. 1, p. 6, 2007, in English.

[60] M. Bustamante, S. Petersson, J. Eriksson et al., "Atlas-based analysis of 4D flow CMR: automated vessel segmentation and flow quantification," Journal of Cardiovascular Magnetic Resonance, vol. 17, no. 1, p. 12, 2015, in English.

[61] X. H. Zhuang, K. S. Rhode, R. S. Razavi, D. J. Hawkes, and S. Ourselin, "A registration-based propagation framework for automatic whole heart segmentation of cardiac MRI," IEEE Transactions on Medical Imaging, vol. 29, no. 9, pp. 1612-1625, 2010, in English.

[62] C. Wang, M. Chen, J. M. Zhao, and Y. Liu, "Fusion of color Doppler and magnetic resonance images of the heart," Journal of Digital Imaging, vol. 24, no. 6, pp. 1024-1030, 2011, in English.

[63] B. Weissler, P. Gebhardt, P. M. Dueppenbecker et al., "A digital preclinical PET/MRI insert and initial results," IEEE Transactions on Medical Imaging, vol. 34, no. 11, pp. 22582270, 2015, in English.

[64] T. Kurzendorfer, C. Forman, M. Schmidt, C. Tillmanns, A. Maier, and A. Brost, "Fully automatic segmentation of left ventricular anatomy in 3-D LGE-MRI," Computerized Medical Imaging and Graphics, vol. 59, pp. 13-27, 2017, in English.

[65] G. Yang, X. Zhuang, H. Khan et al., "Multitlas propagation based left atrium segmentation coupled with super-voxel based pulmonary veins delineation in late gadoliniumenhanced cardiac MRI," in Proceedings of Medical Imaging 2017: Image Processing, M. A. Styner and E. D. Angelini, Eds., vol. 10133, International Society for Optical Engineering (SPIE), Orlando, FL, USA, February 2017.

[66] A. E. Campbell-Washburn, M. A. Tavallaei, M. Pop et al., "Real-time MRI guidance of cardiac interventions," Journal of Magnetic Resonance Imaging, vol. 46, no. 4, pp. 935-950, 2017, in English.

[67] N. Molko, S. Pappata, J.-F. Mangin et al., "Monitoring disease progression in CADASIL with diffusion magnetic resonance imaging," Stroke, vol. 33, no. 12, pp. 2902-2908, 2002.

[68] G. Helft, S. G. Worthley, V. Fuster et al., "Progression and regression of atherosclerotic lesions: monitoring with serial noninvasive magnetic resonance imaging," Circulation, vol. 105, no. 8, pp. 993-998, 2002.

[69] K. Gilbert, B. R. Cowan, A. Suinesiaputra, C. Occleshaw, and A. A. Young, "Rapid D-Affine biventricular cardiac function with polar prediction," in Proceedings of International Conference on Medical Image Computing and ComputerAssisted Intervention, pp. 546-553, Springer, Boston, MA, USA, September 2014.

[70] G. F. Greil, I. Wolf, A. Kuettner et al., "Stereolithographic reproduction of complex cardiac morphology based on high spatial resolution imaging," Clinical Research in Cardiology, vol. 96, no. 3, pp. 176-185, 2007, in English.

[71] K. Werys, J. Petryka-Mazurkiewicz, Ł. Błaszczyk et al., "Cine dyscontractility index: a novel marker of mechanical dyssynchrony that predicts response to cardiac resynchronization therapy," Journal of Magnetic Resonance Imaging, vol. 44, no. 6, pp. 1483-1492, 2016, in English.

[72] C. Mahnkopf, T. J. Badger, N. S. Burgon et al., "Evaluation of the left atrial substrate in patients with lone atrial fibrillation using delayed-enhanced MRI: implications for disease progression and response to catheter ablation," Heart Rhythm, vol. 7, no. 10, pp. 1475-1481, 2010.
[73] M. F. Santarelli, V. Positano, N. Martini, G. Valvano, and L. Landini, "Technological innovations in magnetic resonance for early detection of cardiovascular diseases," Current Pharmaceutical Design, vol. 22, no. 1, pp. 77-89, 2016.

[74] A. M. Pouch, P. A. Yushkevich, B. M. Jackson, J. H. Gorman, R. C. Gorman, and C. M. Sehgal, "Dynamic shape modelingof the mitral valve from real-ime $3 \mathrm{D}$ ultrasound imagesusing continuous medial representation," in Proceedings of Medical Imaging 2012: Ultrasonic Imaging, Tomography, and Therapy, J. G. Bosch and M. M. Doyley, Eds., vol. 8320, International Society for Optical Engineering (SPIE), San Diego, CA, USA, February 2012.

[75] A. Omran, A. Arifi, and A. Mohamed, "Echocardiography of the mitral valve," Journal of the Saudi Heart Association, vol. 22, no. 3, pp. 165-170, 2010.

[76] F. P. Li, M. Rajchl, J. Moore, and T. M. Peters, "A mitral annulus tracking approach for navigation of off-pump beating heart mitral valve repair," Medical Physics, vol. 42, no. 1, pp. 456-468, 2015.

[77] F. P. Li, M. Rajchl, J. Moore, and T. M. Peters, "Ultrasound based mitral valve annulus tracking for off-pump beating heart mitral valve repair," in Proceedings of Medical Imaging 2014: Image-Guided Procedures, Robotic Interventions, and Modeling, Z. R. Yaniv and D. R. Holmes, Eds., vol. 9036, International Society for Optical Engineering (SPIE), San Diego, CA, USA, March 2014.

[78] D. Barbosa, K. Hristova, D. Loeckx, F. Rademakers, P. Claus, and J. D'Hooge, " $3 \mathrm{D}$ motion and strain estimation of theheart: initial clinical findings," in Proceedings of Medical Imaging 2010: Ultrasonic Imaging, Tomography, and Ther$a p y$, J. D'Hooge and S. A. McAleavey, Eds., vol. 7629, International Society for Optical Engineering (SPIE), San Diego, CA, USA, March 2010.

[79] K. Y. E. Leung, M. van Stralen, M. M. Voormolen et al., "Registration of 2D cardiac images to real-ime 3D ultrasoundvolumes for 3D stress echocardiography," in Proceedings of Medical Imaging 2006: Image Processing, J. M. Reinhardt and J. P. W. Pluim, Eds., vol. 6144, International Society for Optical Engineering (SPIE), Graz, Austria, May 2006.

[80] S. M. Alavi and P. Masaeli, "Automatic detection of coronary artery disease using registration of ultrasound images of the heart (echocardiography)," Turkish Journal of Electrical Engineering and Computer Sciences, vol. 24, no. 4, pp. 2053-2070, 2016, in English.

[81] J. A. White, P. W. Pflugfelder, D. R. Boughner, and W. J. Kostuk, "Validation of a three-dimensional intravascular ultrasound imaging technique to assess atherosclerotic burden: Potential for improved assessment of cardiac allograft, coronary artery disease," Canadian Journal of Cardiology, vol. 19, no. 10, pp. 1147-1153, 2003.

[82] A. Beaton, E. Okello, P. Lwabi, C. Mondo, R. McCarter, and C. Sable, "Echocardiography screening for rheumatic heart disease in Ugandan schoolchildren," Circulation, vol. 126, no. 25, pp. e478-e479, 2012.

[83] E. Marijon, D. S. Celermajer, M. Tafflet et al., "Rheumatic heart disease screening by echocardiography," Circulation, vol. 120, no. 8, pp. 663-668, 2009.

[84] E. Marijon, P. Ou, D. S. Celermajer et al., "Prevalence of rheumatic heart disease detected by echocardiographic screening," New England Journal of Medicine, vol. 357, no. 5, pp. 470-476, 2007.

[85] A. Khalil, Y. M. Liew, S. C. Ng, K. W. Lai, and Y. C. Hum, "Echocardiography to cardiac CT image registration spatial 
and temporal registration of the 2D planar echocardiography images with cardiac CT volume," in Proceedings of 2016 IEEE 18th International Conference on E-Health Networking, Applications and Services (Healthcom), pp. 574-578, Munich, Germany, September 2016.

[86] A. Khalil, A. Faisal, S.-C. Ng, Y. M. Liew, and K. W. Lai, "Mitral valve rigid registration using 2D echocardiography and cardiac computed tomography," in Proceedings of 2017 International Conference on Applied System Innovation (ICASI), Sapporo, Japan, May 2017.

[87] Z. Luo, J. F. Cai, T. M. Peters, and L. X. Gu, "Intra-operative 2-D ultrasound and dynamic 3-D aortic model registration for magnetic navigation of transcatheter aortic valve implantation," IEEE Transactions on Medical Imaging, vol. 32, no. 11, pp. 2152-2165, 2013, in English.

[88] C. A. Linte, A. D. Wiles, N. Hill et al., “An augmented realityenvironment for imageuidance of off-pump mitral valveimplantation," in Proceedings of Medical Imaging 2007: Visualization and Image-Guided Procedures, K. R. Cleary and M. I. Miga, Eds., vol. 6509, International Society for Optical Engineering (SPIE), San Diego, CA, USA, March 2007.

[89] C. A. Linte, J. Moore, A. D. Wiles, C. Wedlake, and T. M. Peters, "Virtual reality-enhanced ultrasound guidance: a novel technique for intracardiac interventions," Computer Aided Surgery, vol. 13, no. 2, pp. 82-94, 2008, in English.

[90] F. P. Li, M. Rajchl, J. A. White, A. Goela, and T. M. Peters, "Ultrasound guidance for beating heart mitral valve repair augmented by synthetic dynamic CT," IEEE Transactions on Medical Imaging, vol. 34, no. 10, pp. 2025-2035, 2015.

[91] F. P. Li, M. Rajchl, J. A. White, A. Goela, and T. M. Peters, "Towards CT enhanced ultrasound guidance for off-pump beating heart mitral valve repair," in Augmented Reality Environments for Medical Imaging and Computer-Assisted Interventions, pp. 136-143, Springer, Berlin, Heidelberg, Germany, 2013.

[92] A. Khalil, A. Faisal, S. C. Ng, Y. M. Liew, and K. W. Lai, "Multimodality registration of two-dimensional echocardiography and cardiac CT for mitral valve diagnosis and surgical planning," Journal of Medical Imaging, vol. 4, no. 3, pp. 1-7, 2017, in English.

[93] A. Khalil, A. Faisal, K. W. Lai, S. C. Ng, and Y. M. Liew, "2D to 3D fusion of echocardiography and cardiac CT for TAVR and TAVI image guidance," Medical \& Biological Engineering \& Computing, vol. 55, no. 8, pp. 1317-1326, 2017.

[94] G. Gao, G. Penney, Y. Ma et al., "Registration of 3D transesophageal echocardiography to X-ray fluoroscopy using image-based probe tracking," Medical Image Analysis, vol. 16, no. 1, pp. 38-49, 2012, in English.

[95] D. Bainbridge, D. L. Jones, G. M. Guiraudon, and T. M. Peters, "Ultrasound image and augmented reality guidance for off-pump, closed, beating, intracardiac surgery," Artificial Organs, vol. 32, no. 11, pp. 840-845, 2008, in English.

[96] J. Grewal, S. Mankad, W. K. Freeman et al., "Real-time threedimensional transesophageal echocardiography in the intraoperative assessment of mitral valve disease," Journal of the American Society of Echocardiography, vol. 22, no. 1, pp. 34-41, 2009.

[97] V. Grau, H. Becher, and J. A. Noble, "Registration of multiview real-time 3-D echocardiographic sequences," IEEE Transactions on Medical Imaging, vol. 26, no. 9, pp. 1154-1165, 2007.
[98] C. R. Hatt, M. T. Tomkowiak, D. A. P. Dunkerley et al., "Depth-resolved registration of transesophageal echo to $\mathrm{x}$-ray fluoroscopy using an inverse geometry fluoroscopy system," Medical Physics, vol. 42, no. 12, pp. 7022-7033, 2015, in English.

[99] F. Boccalandro, E. Baptista, A. Muench, C. Carter, and R. W. Smalling, "Comparison of intracardiac echocardiography versus transesophageal echocardiography guidance for percutaneous transcatheter closure of atrial septal defect," American Journal of Cardiology, vol. 93, no. 4, pp. 437-440, 2004, in English.

[100] P. Peng, K. Lekadir, A. Gooya, L. Shao, S. E. Petersen, and A. F. Frangi, "A review of heart chamber segmentation for structural and functional analysis using cardiac magnetic resonance imaging," Magnetic Resonance Materials in Physics, Biology and Medicine, vol. 29, no. 2, pp. 155-195, 2016.

[101] X. S. Lu, R. Q. Yang, Q. L. Xie, S. X. Ou, Y. F. Zha, and D. F. Wang, "Nonrigid registration with corresponding points constraint for automatic segmentation of cardiac DSCT images," Biomedical Engineering Online, vol. 16, no. 1, 2017.

[102] K. Cai, R. Yang, H. Chen et al., "A framework combining window width-level adjustment and Gaussian filter-based multi-resolution for automatic whole heart segmentation," Neurocomputing, vol. 220, pp. 138-150, 2017.

[103] K. Punithakumar, I. Ben Ayed, M. Afshin et al., "Detecting left ventricular impaired relaxation in cardiac MRI using moving mesh correspondences," Computer Methods and Programs in Biomedicine, vol. 124, pp. 58-66, 2016.

[104] A. Daryanani, S. Dangi, Y. K. Ben-Zikri, and C. A. Linte, "Acomparison study of Atlasased 3D cardiac MRI segmentation:global vs. global \& local transformations," in Proceedings of SPIE, Medical Imaging 2016: Image-Guided Procedures, Robotic Interventions, and Modeling, R. J. Webster and Z. R. Yaniv, Eds., vol. 9786, International Society for Optical Engineering (SPIE), Bellingham, WA, USA, July 2016.

[105] Z. L. Xie, X. Liang, L. Guo et al., "Automatic classification framework for ventricular septal defects: a pilot study on high-throughput mouse embryo cardiac phenotyping," Journal of Medical Imaging, vol. 2, no. 4, article 041003, 2015.

[106] G. Y. Yang, Y. Chen, L. J. Tang, H. Z. Shu, and C. Toumoulin, "Automatic left ventricle segmentation based on multi-Atlas registration in 4D CT images," in Proceedings of 2014 IEEE 11th International Symposium on Biomedical Imaging, pp. 413-416, IEEE, Beijing, China, April 2014.

[107] J. Ehrhardt, T. Kepp, A. Schmidt-Richberg, and H. Handels, "Joint multibject registration and segmentation of left andright cardiac ventricles in 4D cine MRI," in Proceedings of SPIE Medical Imaging 2014: Image Processing, S. Ourselin and M. A. Styner, Eds., vol. 9034, pp. 1010-1024, San Diego, CA, USA, April 2014.

[108] C. M. S. Nambakhsh, J. Yuan, K. Punithakumar et al., "Left ventricle segmentation in MRI via convex relaxed distribution matching," Medical Image Analysis, vol. 17, no. 8, pp. 1010-1024, 2013.

[109] F. Khalifa, G. M. Beache, A. Elnakib et al., "A new shapebased framework for the left ventricle wall segmentation from cardiac first-pass perfusion MRI," in Proceedings of 2013 IEEE 10th International Symposium on Biomedical Imaging, pp. 41-44, New York, NY, USA, April 2013. 
[110] J. B. Partridge and R. H. Anderson, "Left ventricular anatomy: its nomenclature, segmentation, and planes of imaging," Clinical Anatomy, vol. 22, no. 1, pp. 77-84, 2009.

[111] K. Punithakumar, M. Noga, I. Ben Ayed, and P. Boulanger, "Right ventricular segmentation in cardiac MRI with moving mesh correspondences," Computerized Medical Imaging and Graphics, vol. 43, pp. 15-25, 2015.

[112] R. Manzke, C. Meyer, O. Ecabert et al., "Automatic segmentation of rotational X-ray images for anatomic intraprocedural surface generation in atrial fibrillation ablation procedures," IEEE Transactions on Medical Imaging, vol. 29, no. 2, pp. 260-272, 2010.

[113] M. Depa, M. R. Sabuncu, G. Holmvang, R. Nezafat, E. J. Schmidt, and P. Golland, "Robust atlas-based segmentation of highly variable anatomy: left atrium segmentation," in Proceedings of International Workshop on Statistical Atlases and Computational Models of the Heart, pp. 85-94, Springer, Beijing, China, September 2010.

[114] X. Alba, M. Pereanez, C. Hoogendoorn et al., "An algorithm for the segmentation of highly abnormal hearts using a generic statistical shape model," IEEE Transactions on Medical Imaging, vol. 35, no. 3, pp. 845-859, Mar 2016.

[115] S. Verma, S. Adler, A. Berman, A. Duran, and D. Loar, "Localization of fossa ovalis and brockenbrough needle prior to left atrial ablation using three-dimensional mapping with EnSite fusion (TM)," Journal of Interventional Cardiac Electrophysiology, vol. 30, no. 1, pp. 37-44, 2011.

[116] P. Neher, H. Barschdorf, S. Dries et al., "Automatic segmentation of cardiac CTs-personalized atrial models augmented with electrophysiological structures," in Proceedings of International Conference on Functional Imaging and Modeling of the Heart, pp. 80-87, Springer, New York, NY, USA, May 2011.

[117] S. Kim, Y. Chang, and J. B. Ra, "Cardiac image reconstruction via nonlinear motion correction based on partial angle reconstructed images," IEEE Transactions on Medical Imaging, vol. 36, no. 5, pp. 1151-1161, 2017.

[118] K. Muller, A. K. Maier, C. Schwemmer et al., "Image artefact propagation in motion estimation and reconstruction in interventional cardiac C-arm CT," Physics in Medicine and Biology, vol. 59, no. 12, pp. 3121-3138, 2014.

[119] M. Unberath, A. Aichert, S. Achenbach, and A. Maier, "Consistency-based respiratory motion estimation in rotational angiography," Medical Physics, vol. 44, no. 9, pp. e113-e124, 2017.

[120] J. W. Yao, T. Sakaguchi, O. Yousuf et al., "Linear quantificationcorrection for myocardial perfusion imaging fromxay coronary angiography," in Proceedings of 2012 IEEE Nuclear Science Symposium and Medical Imaging Conference Record, B. Yu, Ed., pp. 2977-2982, IEEE, New York, NY, USA, October 2012.

[121] C. D. Stone, J. W. McCormick, D. R. Gilland, K. L. Greer, R. E. Coleman, and R. J. Jaszczak, "Effect of registration Errors between transmission and emission scans on a SPECT system using sequential scanning," Journal of Nuclear Medicine, vol. 39, no. 2, pp. 365-373, 1998.

[122] C. Kolbitsch, M. A. Ahlman, C. Davies-Venn et al., "Cardiac and respiratory motion correction for simultaneous cardiac PET/MR," Journal of Nuclear Medicine, vol. 58, no. 5, pp. 846-852, 2017.

[123] F. Lamare, A. Le Maitre, M. Dawood et al., "Evaluation of respiratory and cardiac motion correction schemes in dual gated PET/CT cardiac imaging," Medical Physics, vol. 41, no. 7 , article $072504,2014$.
[124] Y. Petibon, N. J. Guehl, T. G. Reese et al., "Impact of motion and partial volume effects correction on PET myocardial perfusion imaging using simultaneous PET-MR," Physics in Medicine and Biology, vol. 62, no. 2, pp. 326-343, 2017.

[125] A. Turco, O. Gheysens, J. Nuyts et al., "Impact of CT-based attenuation correction on the registration between dualgated cardiac PET and high-resolution CT," IEEE Transactions on Nuclear Science, vol. 63, no. 1, pp. 180-192, 2016.

[126] A. A. Isola, U. van Stevendaal, D. Schaefer, W. J. Niessen, and M. Grass, "Cardiacotion correction for helical CT," in Proceedings of 2009 IEEE Nuclear Science Symposium Conference Record, B. Yu, Ed., vol. 1-5, pp. 3247-3250, Orlando, FL, USA, October 2009.

[127] S. J. Martin, J. Dey, M. A. King, and B. F. Hutton, "Segmenting and tracking diaphragm and heart regions in gatedCT datasets as an aid to developing a predictive model for respiratory motion-correction,"in Proceedings of 2007 IEEENuclear Science Symposium Conference Record, vol. 1-11, p. 2680, IEEE, Honolulu, HI, USA, October-November 2007.

[128] M. Prummer, R. Fahrig, L. Wigström et al., "Cardiac C-arm CT: 4D non-model based heart motion estimation and its application," Edited by J. Hsieh and M. J. Flynn, Eds., in Proceedings of SPIE Medical Imaging 2007: Physics of Medical Imaging, Pts 1-3, vol. 6510, March 2007.

[129] C. Rohkohl, H. Bruder, K. Stierstorfer, and T. Flohr, "Improving best-phase image quality in cardiac CT by motion correction with MAM optimization," Medical Physics, vol. 40, no. 3, article 031901, 2013.

[130] M. S. Hansen, T. S. Sorensen, A. E. Arai, and P. Kellman, "Retrospective reconstruction of high temporal resolution cine images from real-time MRI using iterative motion correction," Magnetic Resonance in Medicine, vol. 68, no. 3, pp. 741-750, 2012.

[131] F. Khalifa, G. M. Beache, A. Firjani, K. C. Welch, G. Gimel'farb, and A. El-Baz, "A new nonrigid registration approach for motion correction of cardiac first-pass perfusion MRI," in Proceedings of 2012 IEEE International Conference on Image Processing, pp. 1665-1668, Orland, FL, USA, September 2012.

[132] M. Li, H. Gupta, S. G. Lloyd, L. J. Dell'Italia, and T. S. Denney, "A graph theoretic approach for computing 3D +time biventricular cardiac strain from tagged MRI data," Medical Image Analysis, vol. 35, pp. 46-57, 2017.

[133] F. Odille, J. M. Escanye, D. Atkinson, L. Bonnemains, and J. Felblinger, "Nonrigid registration improves MRI T-2 quantification in heart transplant patient follow-up," Journal of Magnetic Resonance Imaging, vol. 42, no. 1, pp. 168-174, 2015.

[134] M. van de Giessen, Q. Tao, R. J. van der Geest, and B. P. F. Lelieveldt, "Model-based alignment of look-locker MRI sequences for calibrated myocardical scar tissue quantification," in Proceedings of 2013 IEEE 10th International Symposium on Biomedical Imaging, pp. 10381041, IEEE, New York, NY, USA, April 2013.

[135] R. Xu, P. Athavale, P. Krahn et al., "Feasibility study of respiratory motion modeling based correction for MRIguided intracardiac interventional procedures," IEEE Transactions on Biomedical Engineering, vol. 62, no. 12, pp. 2899-2910, 2015.

[136] J. Betancur, A. Simon, E. Halbert et al., "Registration of dynamic multiview 2D ultrasound and late gadolinium enhanced images of the heart: Application to hypertrophic 
cardiomyopathy characterization," Medical Image Analysis, vol. 28, pp. 13-21, 2016.

[137] A. P. King, C. Jansen, K. S. Rhode, D. Caulfield, R. S. Razavi, and G. P. Penney, "Respiratory motion correction for imageguided cardiac interventions using 3-D echocardiography," Medical Image Analysis, vol. 14, no. 1, pp. 21-29, 2010.

[138] C. F. Baumgartner, C. Kolbitsch, J. R. McClelland, D. Rueckert, and A. P. King, "Autoadaptive motion modelling for MR-based respiratory motion estimation," Medical Image Analysis, vol. 35, pp. 83-100, 2017.

[139] F. Li, P. Lang, M. Rajchl, E. C. S. Chen, G. Guiraudon, and T. M. Peters, "Towards real-ime 3D US-T registration onthe beating heart for guidance of minimally invasive cardiacinterventions," in Proceedings of SPIE Medical Imaging 2012: Image-Guided Procedures, Robotic Interventions, and Modeling, D. R. Holmes and K. H. Wong, Eds., vol. 8316, San Diego, CA, USA, February 2012.

[140] C. A. Linte, M. Wierzbicki, J. Moore, S. H. Little, G. M. Guiraudon, and T. M. Peters, "Towards subjectspecific models of the dynamic heart for image-guided mitral valve surgery," in Proceedings of International Conference on Medical Image Computing and Computer-Assisted Intervention, pp. 94-101, Springer, Brisbane, Australia, October-November 2007.

[141] M. Figl, D. Rueckert, and P. Edwards, "Registration ofa cardiac motion model to video for augmented reality imageguidance of coronary artery bypass," in Proceedings of IFMBE World Congress on Medical Physics and Biomedical Engineering, vol. 25, Pt 4: Image Processing, Biosignal Processing, Modelling and Simulation, Biomechanics, O. Dossel and W. C. Schlegel, Eds., vol. 25, pp. 1692-1694, Munich, Germany, September 2009.

[142] F. P. Li, M. Rajchl, J. A. White, A. Goela, and T. M. Peters, "Generation of synthetic 4D cardiac CT images for guidance of minimally invasive beating heart interventions," in Proceedings of International Conference on Information Processing in Computer-Assisted Interventions, vol. 7915, pp. 11-20, Springer, Heidelberg, Germany, June 2013.

[143] X. S. Huang, J. Moore, G. Guiraudon et al., "Dynamic 2D ultrasound and 3D CT image registration of the beating heart," IEEE Transactions on Medical Imaging, vol. 28, no. 8, pp. 1179-1189, 2009.

[144] A. Khalil, A. Faisal, S. C. Ng, Y. M. Liew, and K. W. Lai, "Multimodality registration of two-dimensional echocardiography and cardiac CT for mitral valve diagnosis and surgical planning," Journal of Medical Imaging, vol. 4, no. 3, article 037001, 2017.

[145] Q. Zhang, X. Huang, R. Eagleson, G. Guiraudon, and T. M. Peters, "Real-ime dynamic display of registered 4Dcardiac MR and ultrasound images using a GPU," in Proceedings of SPIE Medical Imaging 2007: Visualization and Image-Guided Procedures, Pts 1 and 2, K. R. Cleary and M. I. Miga, Eds., vol. 6509, San Diego, CA, USA, March 2007.

[146] C. A. Linte, M. Wierzbicki, J. Moore et al., "From preoperativecardiac modeling to intraperative virtual environmentsfor surgical guidance: an in vivo study," in Proceedings of SPIE Medical Imaging 2008: Visualization, Image-Guided Procedures, and Modeling, Pts 1 and 2, M. I. Miga and K. R. Cleary, Eds., vol. 6918, International Society for Optical Engineering (SPIE), San Diego, CA, USA, March 2008.

[147] F. Tavard, A. Simon, C. Leclercq, E. Donal, A. I. Hernandez, and M. Garreau, "Multimodal registration and data fusion for cardiac resynchronization therapy optimization," IEEE
Transactions on Medical Imaging, vol. 33, no. 6, pp. 13631372, 2014.

[148] S. Goetze and R. L. Wahl, "Prevalence of misregistration between SPECT and CT for attenuation-corrected myocardial perfusion SPECT," Journal of Nuclear Cardiology, vol. 14, no. 2, pp. 200-206, 2007.

[149] M. D. Gilman, A. J. Fischman, V. Krishnasetty, E. F. Halpern, and S. L. Aquino, "Hybrid PET/CT of the thorax: when is computer registration necessary?," Journal of Computer Assisted Tomography, vol. 31, no. 3, pp. 395-401, 2007.

[150] K. L. Gould, T. Pan, C. Loghin, N. P. Johnson, A. Guha, and S. Sdringola, "Frequent diagnostic errors in cardiac PET/CT due to misregistration of CT attenuation and emission PET images: a definitive analysis of causes, consequences, and corrections," Journal of Nuclear Medicine, vol. 48, no. 7, pp. 1112-1121, 2007

[151] M. Marinelli, F. Tucci, V. Positano, D. Neglia, and L. Landini, "A new multi-esolution optimization algorithm for PETTcardiac images registration," in Proceedings of IFMBE World Congress on Medical Physics and Biomedical Engineering, vol. 25, Pt 4: Image Processing, Biosignal Processing, Modelling and Simulation, Biomechanics, O. Dossel and W. C. Schlegel, Eds., vol. 25, pp. 414-417, Munich, Germany, September 2009.

[152] C. Rafael Gonzalez and R. Woods, Digital Image Processing, Pearson Education, London, UK, 2002.

[153] L. Ibanez, W. Schroeder, L. Ng, and J. Cates, The Insight Segmentation And Registration Toolkit, Software Guide, 2015.

[154] E. Ferrante, V. Fecamp, and N. Paragios, "Slice-to-volume deformable registration: efficient one-shot consensus between plane selection and in-plane deformation," International Journal of Computer Assisted Radiology and Surgery, vol. 10, no. 6, pp. 791-800, 2015.

[155] M. Figl, D. Rueckert, D. Hawkes et al., "Image guidance for robotic minimally invasive coronary artery bypass," in Proceedings of International Workshop on Medical Imaging and Virtual Reality, pp. 202-209, Springer, Tokyo, Japan, August 2008.

[156] M. Figl, D. Rueckert, D. Hawkes et al., "Image guidance for robotic minimally invasive coronary artery bypass," Computerized Medical Imaging and Graphics, vol. 34, no. 1, pp. 61-68, 2010.

[157] S. Hamrouni, N. Rougon, and F. Preteux, "Groupwiseregistration of cardiac perfusion MRI sequences usingnormalized mutual information in high dimension," in Proceedings of SPIE Medical Imaging 2011: Image Processing, B. M. Dawant and D. R. Haynor, Eds., vol. 7962, International Society for Optical Engineering (SPIE), Orlando, FL, USA, March 2011.

[158] B. Heyde, D. Barbosa, R. Jasaityte et al., "Three-dimensional myocardial strain estimation from volumetric ultrasound data using a novel transformation model adapted to the heart," in Proceedings of 2012 IEEE International Ultrasonics Symposium, pp. 1086-1089, IEEE, Dresden, Germany, October 2012.

[159] K. Lekadir, C. Hoogendoorn, N. Duchateau, and A. F. Frangi, "Construction of a statistical atlas of the wholeheart from a large 4D CT database," in Proceedings of 2012 Computing in Cardiology, A. Murray, Ed., vol. 39, pp. 541-544, IEEE, Kraków, Poland, September 2012.

[160] B, Li, B. R. Cowan, and A. A. Young, "Real time myocardial strain analysis of tagged MR cines using element space nonrigid registration," in Proceedings of Asian Conference on 
Computer Vision, vol. 6495, pp. 385-396, Springer, Queenstown, New Zealand, November, 2010.

[161] L. Livieratos, L. Stegger, P. M. Bloomfield, K. Schafers, D. L. Bailey, and P. G. Camici, "Rigidody transformationof listode projection data for respiratory motion correctionin cardiac PET," in Proceedings of 2003 IEEE Nuclear Science Symposium, Conference Record, S. D. Metzler, Ed., vol. 1-5, pp. 2183-2187, IEEE, Portland, OR, USA, July 2004.

[162] M. Lorenzo-Valdés, G. I. Sanchez-Ortiz, R. Mohiaddin, and D. Rueckert, "Atlas-based segmentation and tracking of 3D cardiac MR images using non-rigid registration," in Proceedings of International Conference on Medical Image Computing and Computer-Assisted Intervention, pp. 642650, Springer, Tokyo, Japan, September, 2002.

[163] K. McLeod, M. Sermesant, P. Beerbaum, and X. Pennec, "Spatio-temporal tensor decomposition of a polyaffine motion model for a better analysis of pathological left ventricular dynamics," IEEE Transactions on Medical Imaging, vol. 34, no. 7, pp. 1562-1575, 2015.

[164] I. Polycarpou, I. Chrysanthou-Baustert, O. Demetriadou et al., "Impact of respiratory motion correction on SPECT myocardial perfusion imaging using a mechanically moving phantom assembly with variable cardiac defects," Journal of Nuclear Cardiology, vol. 24, no. 4, pp. 1216-1225, 2017.

[165] J. Cammin and K. Taguchi, "Image-based motion estimationfor cardiac CT via image registration," in Proceedings of SPIE Medical Imaging 2010: Image Processing, B. M. Dawant and D. R. Haynor, Eds., vol. 7623, International Society for Optical Engineering (SPIE), San Diego, CA, USA, March 2010.

[166] M. Erbacher, G. Korosoglou, R. Floca, and H. Dickhaus, "Compensation of cardiac motion in angiographic sequencesfor the assessment of myocardial perfusion," in Proceedings of 4th European Conference of the International Federation for Medical and Biological Engineering, J. VanderSloten, P. Verdonck, M. Nyssen, and J. Haueisen, Eds., vol. 22, no. 1-3, pp. 693-696, Springer, Antwerp, Belgium, November 2009.

[167] D. Manke, P. Rosch, K. Nehrke, P. Bornert, and O. Dossel, "Model evaluation and calibration for prospective respiratory motion correction in coronary MR angiography based on 3-D image registration," IEEE Transactions on Medical Imaging, vol. 21, no. 9, pp. 1132-1141, 2002.

[168] T. Mansoori, G. Plank, R. Burton et al., "An iterative method for registration of high-resolution cardiac histoanatomical and MRI images," in Proceedings of 2007 4th IEEE International Symposium on Biomedical Imaging: Macro to Nano, vol. 1-3, p. 572, IEEE, Arlington, VA, USA, April 2007.

[169] V. Tavakoli, M. S. Nambakhsh, N. Sahba, and A. Makinian, "A new variational technique for combining affine registration and optical flow in echocardiography images," in Proceedings of 2008 30th Annual International Conference of the IEEE Engineering in Medicine and Biology Society, vol. 18, pp. 205, IEEE, Vancouver, BC, Canada, August 2008.

[170] A. A. Amini, Y. S. Chen, R. W. Curwen, V. Mani, and J. Sun, "Coupled B-snake grids and constrained thin-plate splines for analysis of 2-D tissue deformations from tagged MRI," IEEE Transactions on Medical Imaging, vol. 17, no. 3, pp. 344-356, 1998.

[171] T. Chen, S. Chung, and L. Axel, "2D motion analysis of long axis cardiac tagged MRI," in Proceedings of International Conference on Medical Image Computing and Computer-
Assisted Intervention, pp. 469-476, Springer, Quebec City, QC, Canada, 2007.

[172] T. Chen, X. Wang, D. Metaxas, and L. Axel, "Fast motion tracking of tagged MRI using angle-preserving meshless registration," in Proceedings of International Conference on Medical Image Computing and Computer-Assisted Intervention, pp. 313-320, Springer, Quebec City, QC, Canada, September 2008.

[173] Y. N. Lu, Y. Sun, R. Liao, and S. H. Ong, "A pre-operative CT and non-contrast-enhanced $\mathrm{C}$-arm $\mathrm{CT}$ registration framework for trans-catheter aortic valve implantation," Computerized Medical Imaging and Graphics, vol. 38, no. 8, pp. 683-695, 2014, in English.

[174] P. Morais, S. Queirós, A. Ferreira et al., "Dense motion field estimation from myocardial boundary displacements," International Journal for Numerical Methods in Biomedical Engineering, article e02758, 2016, in English.

[175] B. Quatember, M. Mayr, W. Recheis et al., "Geometric modeling and motion analysis of the epicardial surface of the heart," Mathematics and Computers in Simulation, vol. 81, no. 3, pp. 608-622, 2010, in English.

[176] N. Rougon, C. Petitjean, F. Preteux, P. Cluzel, and P. Grenier, "A non-rigid registration approach for quantifying myocardial contraction in tagged MRI using generalized information measures," Medical Image Analysis, vol. 9, no. 4, pp. 353-375, Aug 2005, in English.

[177] I. Smal, N. Carranza-Herrezuelo, S. Klein et al., "Reversible jump MCMC methods for fully automatic motion analysis in tagged MRI," Medical Image Analysis, vol. 16, no. 1, pp. 301-324, 2012, in English.

[178] M. Taron, N. Paragios, and M. P. Jolly, "From uncertainties to statistical model building and segmentation of the left ventricle," in Proceedings of 2007 IEEE 11th International Conference on Computer Vision (IEEE International Conference on Computer Vision, vol. 1-6, IEEE, p. 2346, Rio De Janeiro, Brazil, October 2007.

[179] B. Yang, W. K. Wong, C. Liu, and P. Poignet, "3D soft-tissue tracking using spatial-color joint probability distribution and thin-plate spline model," Pattern Recognition, vol. 47, no. 9, pp. 2962-2973, 2014, in English.

[180] B. M. White, A. Santhanam, D. Thomas et al., "Modeling and incorporating cardiac-induced lung tissue motion in a breathing motion model," Medical Physics, vol. 41, no. 4, article 043501, 2014, in English.

[181] R. Casero, U. Siedlecka, E. S. Jones et al., "Transformation diffusion reconstruction of three-dimensional histology volumes from two-dimensional image stacks," Medical Image Analysis, vol. 38, pp. 184-204, 2017, in English.

[182] B. Heyde, M. Alessandrini, J. Hermans, D. Barbosa, P. Claus, and J. D'Hooge, "Anatomical image registration using volume conservation to assess cardiac deformation from $3 \mathrm{D}$ ultrasound recordings," IEEE Transactions on Medical Imaging, vol. 35, no. 2, pp. 501-511, 2016, in English.

[183] P. Morais, S. Queiros, B. Heyde, J. Engvall, J. D’Hooge, and J. L. Vilaca, "Fully automatic left ventricular myocardial strain estimation in $2 \mathrm{D}$ short-axis tagged magnetic resonance imaging," Physics in Medicine and Biology, vol. 62, no. 17, pp. 6899-6919, 2017, in English.

[184] H. Yousefi-Banaem, S. Kermani, S. Asiaei, and H. Sanei, "Prediction of myocardial infarction by assessing regional cardiac wall in CMR images through active mesh modeling," Computers in Biology and Medicine, vol. 80, pp. 56-64, 2017, in English. 
[185] S. Bhat, I. V. Larina, K. V. Larin, M. E. Dickinson, and M. Liebling, "Multiple-cardiac-cycle noise reduction in dynamic optical coherence tomography of the embryonic heart and vasculature," Optics Letters, vol. 34, no. 23, pp. 3704-3706, 2009, in English.

[186] A. A. Isola, H. Schmitt, U. van Stevendaal et al., "Image registration and analysis for quantitative myocardial perfusion: application to dynamic circular cardiac CT," Physics in Medicine and Biology, vol. 56, no. 18, pp. 5925-5947, 2011, in English.

[187] C. Li, Y. Sun, and P. Chai, "Pseudo ground truth based nonrigid registration of myocardial perfusion MRI," Medical Image Analysis, vol. 15, no. 4, pp. 449-459, 2011, in English.

[188] G. Kiss, S. Ford, P. Claus, J. D’Hooge, and H. Torp, “Fusion of $3 \mathrm{D}$ echo and cardiac magnetic resonance volumes during live scanning," in Proceedings of 2013 IEEE International Ultrasonics Symposium (IEEE International Ultrasonics Symposium, pp. 824-827, IEEE, Prague, Czech Republic, July 2013.

[189] D. Neumann, S. Grbic, M. John, N. Navab, J. Hornegger, and R. Ionasec, "Probabilistic sparse matching for robust 3D/3D fusion in minimally invasive surgery," IEEE Transactions on Medical Imaging, vol. 34, no. 1, pp. 49-60, 2015, in English.

[190] C. Jia, R. Olafsson, K. Kim et al., "2D Speckle Tracking vs DTI-derived Elasticity Imaging on an Isolated Rabbit Heart," in Proceedings of 2008 IEEE Ultrasonics Symposium, vol. 1-4, IEEE, Beijing, China, November 2008.

[191] X. L. Qin, S. Wang, M. Shen et al., "Register cardiac fiberorientations from 3D DTI volume to 2D ultrasound image ofrat hearts," in Proceedings of Medical Imaging 2015: Image-Guided Procedures, Robotic Interventions, and Modeling, vol. 9415, Z. R. Yaniv and R. J. Webster, Eds., International Society for Optical Engineering (SPIE), Orlando, FL, USA, March 2015.

[192] M. Lorenzo-Valdés, G. I. Sanchez-Ortiz, A. G. Elkington, R. H. Mohiaddin, and D. Rueckert, "Segmentation of 4D cardiac MR images using a probabilistic atlas and the EM algorithm," Medical Image Analysis, vol. 8, no. 3, pp. 255265, 2004

[193] H. Bruder, C. Rohkohl, T. Allmendinger et al., "Can motioncompensated reconstruction improve 'best phase' reconstructionin cardiac CT?," in Proceedings of Medical Imaging 2013: Physics of Medical Imaging, vol. 8668, R. M. Nishikawa, B. R. Whiting, and C. Hoeschen, Eds., International Society for Optical Engineering (SPIE), San Diego, CA, USA, March 2013.

[194] D. Likhite, G. Adluru, and E. DiBella, "Deformable and rigid model-based image registration for quantitative cardiac perfusion," in Proceedings of International Workshop on Statistical Atlases and Computational Models of the Heart, pp. 41-50, Springer, Quebec City, QC, Canada, September 2014.

[195] J. M. Mukherjee, B. F. Hutton, K. L. Johnson, P. H. Pretorius, and M. A. King, "An evaluation of data-driven motion estimation in comparison to the usage of external-surrogates in cardiac SPECT imaging," Physics in Medicine and Biology, vol. 58, no. 21, pp. 7625-7646, 2013, in English.

[196] K. Muller, C. Rohkohl, G. Lauritsch et al., "4- motion fieldestimation by combined multiple heart phase registration (cmhpr) for cardiac Crm data," in Proceedings of 2012 IEEE Nuclear Science Symposium and Medical Imaging Conference Record (IEEE Nuclear Science Symposium Conference Record), B. Yu, Ed., pp. 3707-3712, IEEE, Anaheim, CA, USA, October 2012.
[197] G. Tarroni, "Automated tracking of deformable objects basedon non-igid registration of cardiac images," in 2012 Computing in Cardiology: Computing in Cardiology Series, vol. 39, A. Murray, Ed., pp. 693-696, IEEE, New York, NY, USA, 2012.

[198] J. Betancur, A. Simon, B. Langella, C. Leclercq, A. Hernandez, and M. Garreau, "Synchronization and registration of cine magnetic resonance and dynamic computed tomography images of the heart," IEEE Journal of Biomedical and Health Informatics, vol. 20, no. 5, pp. 1369-1376, 2016.

[199] Y. Chenoune, C. Pellot-Barakat, C. Constantinides et al., "Methodology for jointly assessing myocardial infarct extent and regional contraction in 3-D CMRI," IEEE Transactions on Biomedical Engineering, vol. 59, no. 9, pp. 2650-2659, 2012.

[200] C. Hoogendoorn, N. Duchateau, D. Sanchez-Quintana et al., "A high-resolution atlas and statistical model of the human heart from multislice CT," IEEE Transactions on Medical Imaging, vol. 32, no. 1, pp. 28-44, 2013.

[201] F. Khalifa, G. M. Beache, G. Gimel'farb, and A. El-Baz, “A new nonrigid registration framework for improved visualization of transmural perfusion gradients on cardiac firstpass perfusion MRI," in Proceedings of 2012 9th IEEE International Symposium on Biomedical Imaging (ISBI), pp. 828-831, IEEE, Barcelona, Spain, May 2012.

[202] F. Khalifa, G. M. Beache, G. Gimel'farb, and A. El-Baz, “A novel CAD system for analyzing cardiac first-pass MR images," in Proceedings of 2012 21st International Conference on Pattern Recognition (International Conference on Pattern Recognition), pp. 77-80, Tsukuba, Japan, November 2012.

[203] S. S. Mokri, M. I. Saripan, M. H. Marhaban, A. J. Nordin, and S. Hashim, "Hybrid registration of PET/CT in thoracic region with pre-filtering PET sinogram," Radiation Physics and Chemistry, vol. 116, pp. 300-304, 2015.

[204] K. C. L. Wong, M. Tee, M. Chen, D. A. Bluemke, R. M. Summers, and J. H. Yao, "Myocardial strain estimationfrom CT: towards computerided diagnosis on infarctionidentification," in Proceedings of Medical Imaging 2015: Computer-Aided Diagnosis, L. M. Hadjiiski and G. D. Tourassi, Eds., vol. 9414, International Society for Optical Engineering (SPIE), Orlando, FL, USA, March 2015.

[205] B. Li, A. A. Young, and B. R. Cowan, "GPU accelerated nonrigid registration for the evaluation of cardiac function," in Proceedings of International Conference on Medical Image Computing and Computer-Assisted Intervention, pp. 880887, Springer, New York, NY, USA, September 2008.

[206] L. M. Bidaut and J. P. Vallee, "Automated registration of dynamic MR images for the quantification of myocardial perfusion," Journal of Magnetic Resonance Imaging, vol. 13, no. 4, pp. 648-655, 2001.

[207] A. F. Frangi, D. Rueckert, J. A. Schnabel, and W. J. Niessen, "Automatic construction of multiple-object threedimensional statistical shape models: application to cardiac modeling," IEEE Transactions on Medical Imaging, vol. 21, no. 9, pp. 1151-1166, 2002.

[208] M. J. Ledesma-Carbayo, J. Kybic, M. Desco et al., "Spatiotemporal nonrigid registration for ultrasound cardiac motion estimation," IEEE Transactions on Medical Imaging, vol. 24, no. 9, pp. 1113-1126, 2005. 


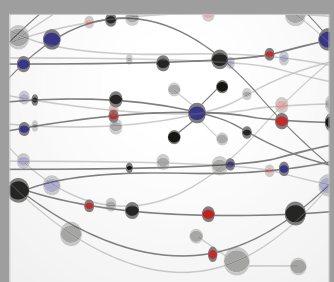

The Scientific World Journal
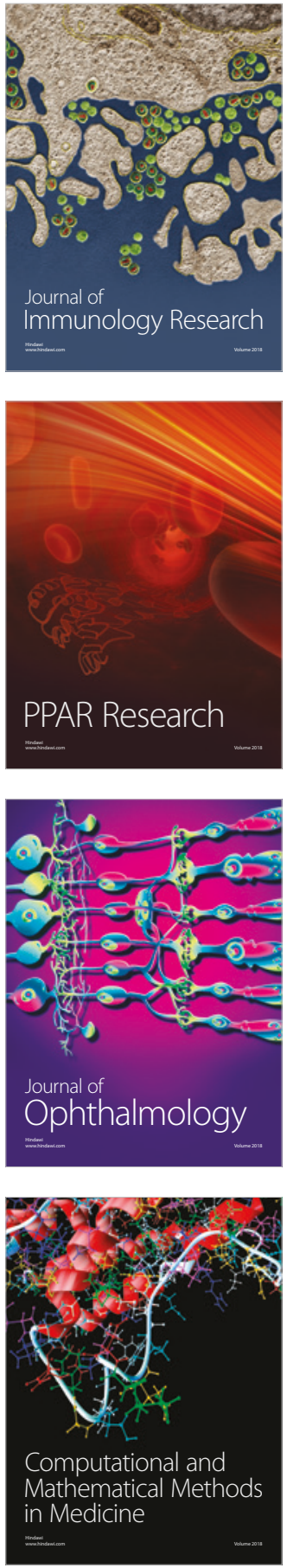

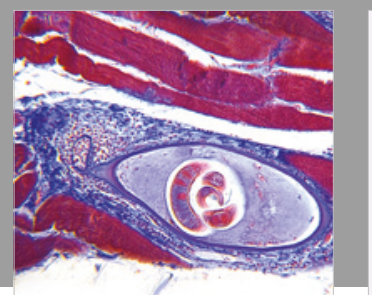

Gastroenterology Research and Practice

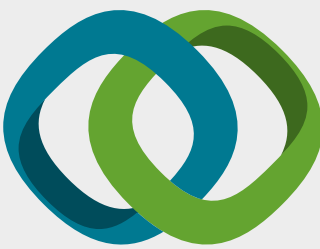

\section{Hindawi}

Submit your manuscripts at

www.hindawi.com
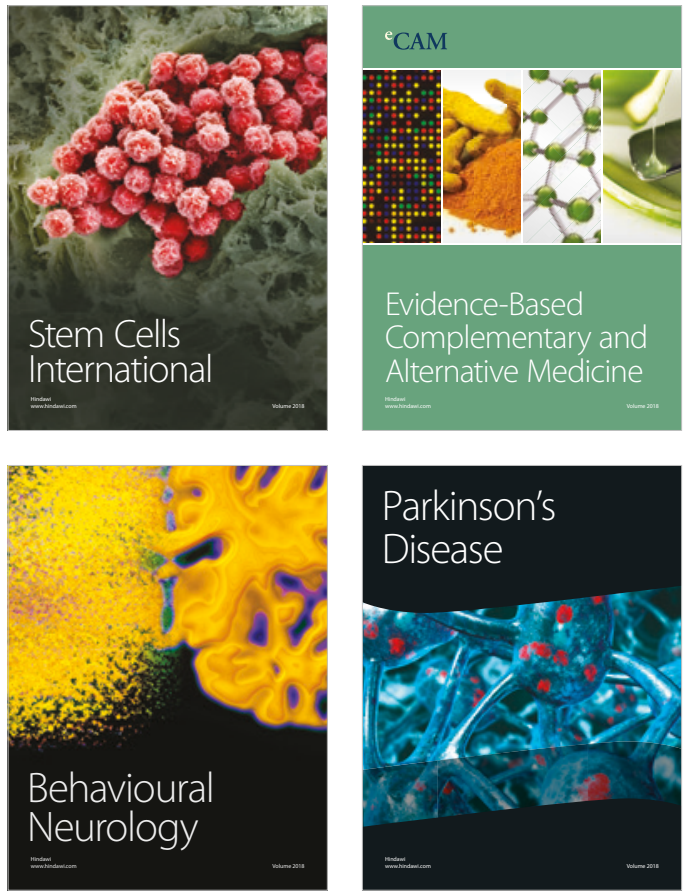

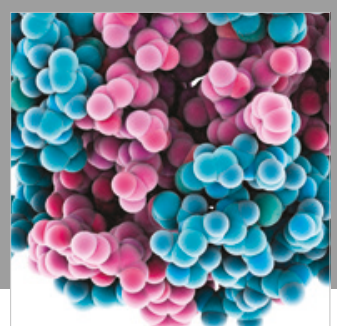

ournal of

Diabetes Research

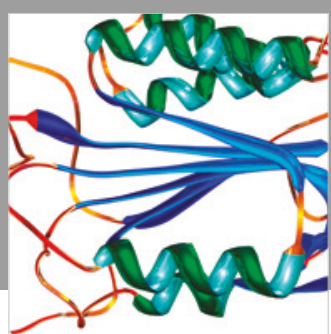

Disease Markers
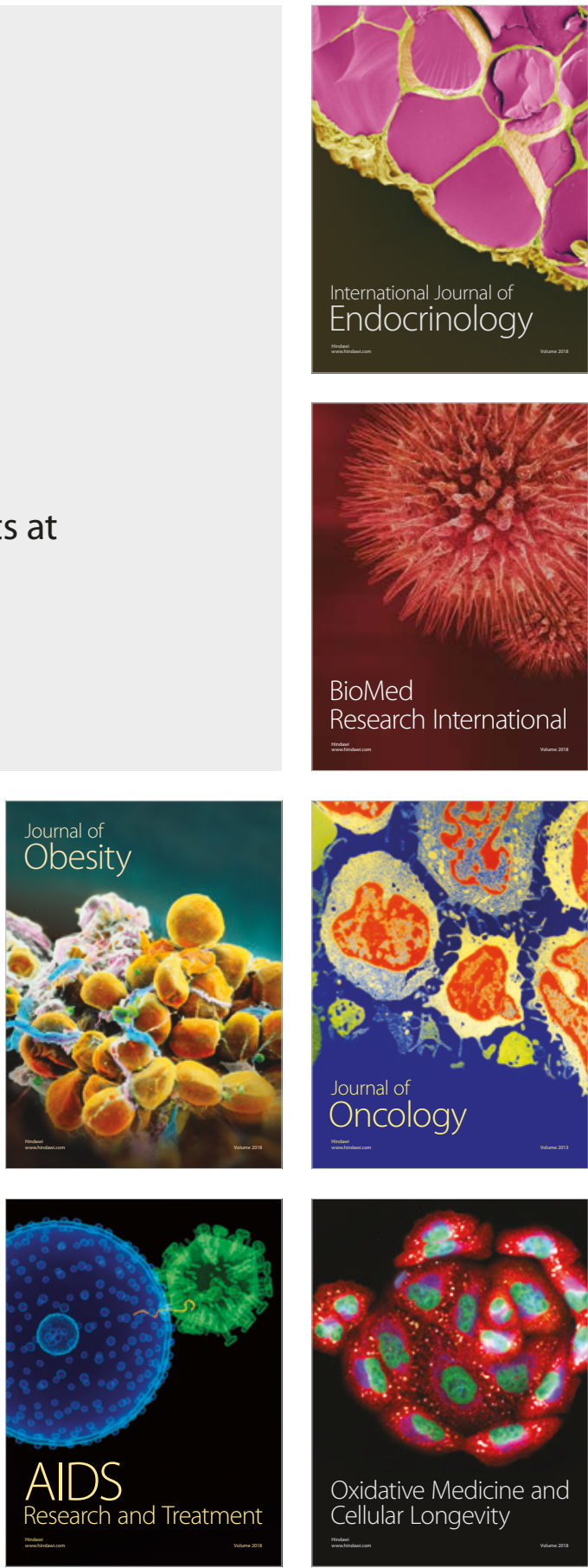